\title{
Levoglucosan kinase involved in citric acid fermentation by Aspergillus niger $C B X-209$ using levoglucosan as sole carbon and energy source
}

\author{
X.L. Zhuang, H.X. Zhang *, J.J. Tang \\ Research Center for Eco-Environmental Sciences, Chinese Academy of Sciences, P.O. Box 2871, Beijing 100085, \\ People's Republic of China
}

Received 17 November 2000

\begin{abstract}
Conditions were optimized for the production of citric acid by a mutant $A$. niger CBX-209 using levoglucosan derived from pyrolysis of wastepaper as a sole carbon and energy source in a simple medium. The optimum concentration of levoglucosan and wheat bran in the medium was $8 \%$ and $3 \%$, respectively, at an optimum initial pH between 5.5 and 6.0 at $35^{\circ} \mathrm{C}$. During fermentation, direct formation of glucose 6-phosphate from levoglucosan in the presence of ATP and $\mathrm{Mg}^{2+}$ as observed by HPLC in the reaction with both cell extracts and partially purified enzyme, suggested that the enzyme acting on levoglucosan is a kinase. Time-course changes in the levels of this special levoglucosan kinase in A. niger CBX-209 grown on levoglucosan and glucose revealed that levoglucosan kinase was an inductive enzyme. (c) 2001 Elsevier Science Ltd. All rights reserved.
\end{abstract}

Keywords: Levoglucosan; Pyrolysis; Aspergillus niger; Citric acid; Levoglucosan kinase

\section{Introduction}

Levoglucosan (1,6-anhydro- $\beta$-D-glucopyranose $)$ (LG), which is very scarce in nature, can be obtained by the destructive distillation of starch [1,2] and has been used for the synthesis of other carbohydrates including sugar derivatives, dextrin-like polymers, and as a research tool for determining the configuration of anomeric glucosides [3]. Levoglucosan is of special interest now, since it can be derived through pyrolysis

\footnotetext{
* Corresponding author. Tel.: +86-10-6293-6612; fax: +86-106284-9155.

E-mail address: hongxun99@sina.com (H.X. Zhang).
}

of cellulosic materials of very low cost [4-6]. Its production and potential use as a fermentative carbon and energy source in the fermentation industry could lead to the possible commercial utilization of large quantities of cellulosic materials such as wastepaper, waste wood products, straws, etc.

Although it has been recognized that cellulosic materials can be converted by pyrolysis into oils containing high concentrations of LG, the commercial application of this anhydrosugar has been hampered by the presence of substances [7] in the pyrolysis oil that are toxic to the growth or metabolism of microorganisms. Since levoglucosan can now be isolated in crystalline form from pyrolysis mixture $[2,8,9]$, it may be used in fermentation industries. 
Studies have shown that many eucaryotic microorganisms are capable of utilizing LG to grow and even produce useful metabolites even though it is not a natural product in nature. Till now, most tested eucaryotic microorganisms, except two yeast species, can grow on LG media [7]. As to products from LG, Aspergillus terreus converts purified LG to itaconic acid with the same yield and rate as in the conversion from glucose [10]. Five yeast strains tested had the ability to ferment activated charcoal treated pyrolysis tar (containing high concentrations of LG) to ethanol, but their ethanol yields were considerably lower than on glucose [7]. With regard to the metabolism of LG, Kitamura et al. $[11,12]$ found that all tested eucaryotic microorganisms capable of growing on LG directly converted it by phosphorylation into glucose 6-phosphate with a specific kinase. But their metabolites from LG were not reported. Very few procaryotic organisms were found to utilize LG. Yasui et al. [13] selected six colonies from soil that assimilated LG completely in the liquid culture and found that all of them seemed to be coryneform bacteria. Nakahara et al. [14] identified one of these colonies to be the genus Arthrobacter and discovered that a novel enzyme, LG dehydrogenase, catalyzed the dehydrogenation of LG to form 1,6-anhydro- $\beta$-D-ribohexopyranose-3-ulose, using $\mathrm{NAD}^{+}$as an electron acceptor. Glucose was then formed after the action of at least two other enzymes. However, no useful products have been reported by procaryotic organisms growing on LG.

According to the reports from Prosen et al. [7] and Nakagawa et al. [10], Aspergillus niger can grow well on purified or partially purified LG, but its products have not been investigated. This paper describes citric acid fermentation of LG, the verification of the direct formation of glucose 6-phosphate from this special intramolecular glucoside catalyzed by LG kinase, and the changes of activity in LG kinase during the fermentation.

\section{Materials and methods}

\subsection{Microorganisms}

The mutant, Aspergillus niger $C B X-209$, was derived by $\gamma$-ray irradiation of spores of parent strain
$C B X-2$, which has high citric acid productivity using starch as carbon and energy source at an industrial scale [15]. The strain was maintained on LG agar slant at $4^{\circ} \mathrm{C}$ and was subcultured every month. The medium composition for conidia preparation on the agar slants per liter was: LG, $20 \mathrm{~g}$; peptone, $1 \mathrm{~g} ; \mathrm{K}_{2} \mathrm{HPO}_{4}, 1 \mathrm{~g} ; \mathrm{MgSO}_{4} \cdot 7 \mathrm{H}_{2} \mathrm{O}, 0.5 \mathrm{~g}$; and agar, $20 \mathrm{~g}$.

\subsection{Fermentation}

The fermentation media contained only LG and wheat bran with an optimum initial concentration of $8 \%$ and $3 \%$, respectively. The media were dispensed in $50 \mathrm{ml}$ aliquots in $250 \mathrm{ml}$ Erlenmeyer flasks and autoclaved for $20 \mathrm{~min}$ at $121^{\circ} \mathrm{C}$. Flasks were inoculated, each, with $1 \mathrm{ml}$ suspension having about $(1-3) \times 10^{5}$ conidia, incubated at $35^{\circ} \mathrm{C}$ on a rotary shaker at $400 \mathrm{rpm}$. The initial $\mathrm{pH}$ of the medium was adjusted to 6.0 .

\subsection{Substrates and other reagents}

LG, which was obtained through the pyrolysis of wastepaper and purified by the method described by Zhang et al. [8], was recrystallized to more than $98 \%$ purity. Glucose 6-phosphate dehydrogenase, 6-phosphogluconate dehydrogenase, glucose oxidase, peroxidase and glucose 6-phosphatase were purchased from Sigma Co. Ltd. (US). All other reagents were of analytical grade.

\subsection{Assays}

Glucose 6-phosphate and citric acid analysis was performed at $30^{\circ} \mathrm{C}$ on HPLC system (Gilson 712 system, Gilson Medical Electronics Inc., US) equipped with an Elite ODS-18C or a Biorad Aminex HPX-87H column, respectively, and both detected by a refractive index detector. The mobile phase was doubly distilled water or $8 \mathrm{mM} \mathrm{H}_{2} \mathrm{SO}_{4}$ at $1 \mathrm{ml} / \mathrm{min}$, respectively. The titration method was also used for routine determination of citric acid. The microbial growth biomass was measured by weighing mycelia filtered, washed twice with distilled water and then dried at $100^{\circ} \mathrm{C}$ to constant weight.

LG-phosphorylating activity was assayed by measuring glucose 6-phosphate formation with the 
glucose 6-phosphate dehydrogenase coupling system described by Maitra et al. [16] with some modifications, i.e. the reaction mixture consisted of $100 \mathrm{mM}$ LG (or glucose), $2 \mathrm{mM} \mathrm{ATP,} 1 \mathrm{mM} \mathrm{NADP}{ }^{+}, 10 \mathrm{mM}$ $\mathrm{MgCl}_{2}, 1$ unit of glucose 6-phosphate dehydrogenase and triethanolamine buffer was replaced by a $50 \mathrm{mM}$ CHES (2[N-cyclohexylamino]ethanesulfonic acid) buffer (pH 9.3). A non-rate-limiting amount of 6-phosphogluconate dehydrogenase was also added to this system when crude cell extracts were used as the enzyme preparation to avoid the excessive estimation of the activity, which was caused by the additional reduction of NADP with the action of the endogenous 6-phosphogluconate dehydrogenase. Then the value was divided by two. The increase in absorbance at $340 \mathrm{~nm}$ was continuously measured with a constant temperature cell compartment. One unit of LG-kinase activity was expressed as the amount of enzyme catalyzing the reduction of $1 \mu \mathrm{mol}$ of NADP per $\min$ at $30^{\circ} \mathrm{C}$ at $\mathrm{pH}$ 9.3. Protein was measured by the Coomassie brilliant blue dye-binding method described by Bradford [17] with bovine serum albumin as the standard.

LG-hydrolyzing activity was assayed by measuring glucose formation with the glucose oxidase and peroxidase coupling system described by Papadopoulas et al. [18]. Crude cell extracts of $1 \mathrm{ml}$ volume or culture supernatant were mixed with $100 \mathrm{mM}$ LG and incubated in several buffer systems, e.g. $100 \mathrm{mM}$ citrate buffer ( $\mathrm{pH} 2.0$ and 5.0), $50 \mathrm{mM}$ Tris- $\mathrm{HCl}$ buffer ( $\mathrm{pH} 7.1$ ), $100 \mathrm{mM}$ triethanolamine $-\mathrm{HCl} / \mathrm{NaOH}$ buffer (pH 8.0), or $50 \mathrm{mM}$ CHES buffer $(\mathrm{pH} 9.3)$ at $30^{\circ} \mathrm{C}$. The mixture was then heated in a boiling water bath for $5 \mathrm{~min}$ to stop the reaction, and the glucose concentration was measured.

\subsection{Detection of the changes of LG kinase and hexokinase during citric acid fermentation}

Mycelia of $A$. niger $C B X-209$ were grown on glucose (or LG) medium for $24 \mathrm{~h}$ and were transferred to an LG (or glucose) medium and cultivated. Samples during fermentation were centrifuged and washed three times with $50 \mathrm{mM}$ extraction buffer composed of $50 \mathrm{mM}$ CHES (pH 9.3), $1 \mathrm{mM} \beta$-mercaptoethanol, $1 \mathrm{mM}$ EDTA and $0.1 \mathrm{mM}$ phenylmethylsulfonyl fluoride. The cells was then ground in liquid nitrogen with a mortar and pestle. The cell powder was resuspended by the addition of the same extraction buffer at the rate of $3 \mathrm{ml}$ per gram of wet cells, briefly ground again and then centrifuged at $18,000 \times g$. The supernatant was assayed to determine LG-kinase activity.

\section{Results and discussion}

\subsection{Citric acid fermentation on $L G$}

\subsubsection{Optimization of the carbon and nitrogen concentration for A. niger $C B X-209$}

Previous studies with A.niger $C B X-2$ suggested that an initial corn starch concentration between $13.5 \%$ and $14.4 \%$, equivalent to glucose concentration between $15 \%$ and $16 \%$, was optimum for maximum citric acid production [15]. As further studies showed that an initial glucose and wheat bran concentration of $8 \%$ and $2 \%$, respectively, was optimum for citric acid conversion, the LG concentration was first fixed at $8 \%$ to determine the optimum nitrogen (wheat bran) concentration for this mutant (Table 1). Citric acid yield increased (while residual LG decreased) with an increase in the initial wheat bran concentration over a range of $1-3 \%$, and a conversion rate as high as $87 \%$ was obtained at a concentration of $3 \%$, after which, although the amount of LG utilized during fermentation continued to increase, there was a decline in the citric acid yield.

Since results above showed that the optimum nitrogen concentration in the LG medium for this mutant was higher than that in glucose medium, further experiments were carried out to verify whether initial LG concentration of $8 \%$ was optimal for this mutant. By fixing the initial wheat bran concentration at $3 \%$,

Table 1

Effect of wheat bran concentration on citric acid production by A. niger $C B X-209$

\begin{tabular}{lll}
\hline $\begin{array}{l}\text { Initial wheat bran } \\
(\%)\end{array}$ & $\begin{array}{l}\text { Residual LG } \\
(\%)\end{array}$ & $\begin{array}{l}\text { Citric acid yield } \\
(\%)\end{array}$ \\
\hline 1.0 & 2.90 & 45.0 \\
2.0 & 2.03 & 66.9 \\
2.5 & 1.12 & 78.3 \\
3.0 & 0.30 & 87.0 \\
3.5 & 0.25 & 60.1 \\
4.0 & 0.15 & 43.8 \\
\hline
\end{tabular}


Table 2

Effect of LG concentration on citric acid production by A.niger $C B X-209$

\begin{tabular}{lcll}
\hline $\begin{array}{l}\text { Initial LG } \\
(\%)\end{array}$ & $\mathrm{C} / \mathrm{N}$ ratio & $\begin{array}{l}\text { Residual LG } \\
(\%)\end{array}$ & $\begin{array}{l}\text { Citric acid yield } \\
(\%)\end{array}$ \\
\hline 4 & $6.7: 1$ & 0.43 & 68.8 \\
6 & $10.0: 1$ & 0.33 & 82.5 \\
8 & $13.3: 1$ & 0.28 & 87.5 \\
10 & $16.7: 1$ & 3.40 & 55.0 \\
12 & $20.0: 1$ & 8.90 & 12.1 \\
\hline
\end{tabular}

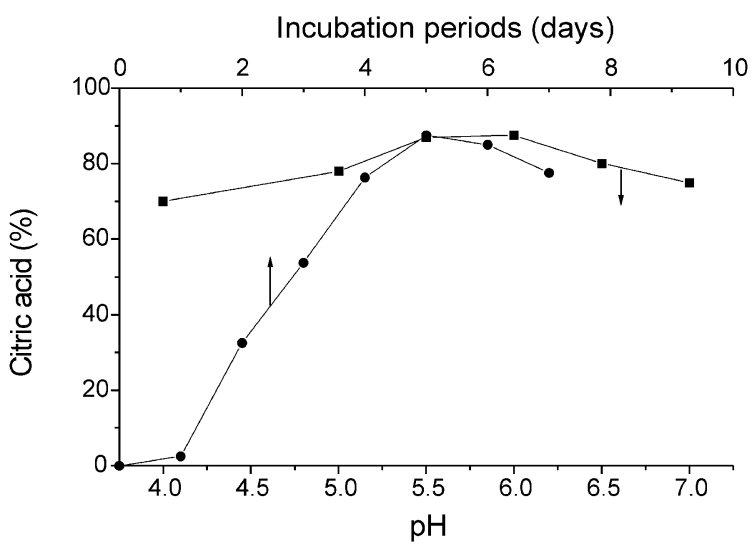

Fig. 1. Effect of initial $\mathrm{pH}$ and incubation period on citric acid fermentation on LG by $A$. niger $C B X-209$. (ם) $\mathrm{pH}$, and incubation periods.

the optimum initial LG concentration was estimated (Table 2). Table 2 showed that increasing the initial LG concentration from $4 \%$ to $8 \%$ resulted in an increased conversion of LG into citric acid, but beyond this point, the yields decreased sharply, as was the case with both $C B X-209$ and $C B X-2$ glucose (citric acid) fermentation (data not shown). Optimum initial sugar concentration for $A$. niger $C B X-209$ in the $\mathrm{LG}$ medium was just the same as that in glucose medium, but best conversion of LG into citric acid occurred at a $\mathrm{C} / \mathrm{N}$ ratio of $13.3: 1$ compared with that of $20: 1$ in glucose medium.

\subsubsection{Effect of initial $p H$, incubation temperature and time}

The optimum $\mathrm{pH}$ for citric acid production by this mutant in LG medium was examined over a range of 3.0-7.0 (Fig. 1). This mutant had no growth at $\mathrm{pH}$ 3.0. Citric acid production occurred with increasing

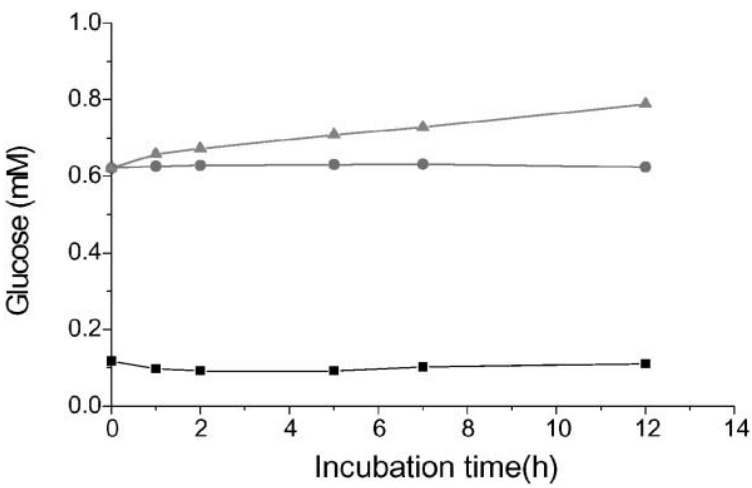

Fig. 2. Detection of the formation of glucose from LG in cell extracts and culture fluids at $30^{\circ} \mathrm{C}$ and an initial LG concentration

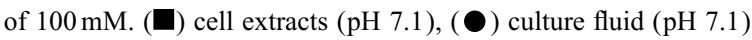
and $(\boldsymbol{\Delta})$ culture fluid $(\mathrm{pH} 2.0)$.

$\mathrm{pH}$, with maximum citric acid production occurring between $\mathrm{pH}$ of 5.5 and 6.0 .

Experiments carried out similarly (not shown) to test the effect of incubation temperature revealed that the optimum temperature was $35^{\circ} \mathrm{C}$, which is nearly the same as that in the glucose media.

Fig. 1 also gave the time course of CBX-209 shake fermentation. Citric acid concentration reached the maximum value on the 5 th day of incubation at $35^{\circ} \mathrm{C}$, after which there was a slight decline.

\subsection{Detection of LG-kinase in A. niger CBX-209}

\subsubsection{Absence of LG-hydrolyzing activity in} A. niger CBX-209 during its citric acid fermentation

Since LG can be hydrolyzed to glucose at low $\mathrm{pH}$, experiments were carried out to verify whether $A$. niger $C B X-209$ employed a special type of LG-hydrolyzing enzyme to utilize LG as carbon and energy source during its citric acid fermentation at a low $\mathrm{pH}$ of about 2 (Fig. 2). Both cell extracts and culture fluids were assayed. Fig. 2 shows that there was no formation of glucose when cell extracts or culture fluids were incubated with $\mathrm{LG}$ in $\mathrm{pH} 7.1$ buffer systems. In other buffer systems at $\mathrm{pH} 5,8$ or 9.3, results were almost the same (data not shown). In culture fluids of $\mathrm{pH} 2$ (Figs. 2 and 3), glucose concentration increased steadily with an increase in both time and temperature. However, the increase of glucose concentration was due to acid hydrolysis and was not caused by LG-hydrolyzing enzyme, because 


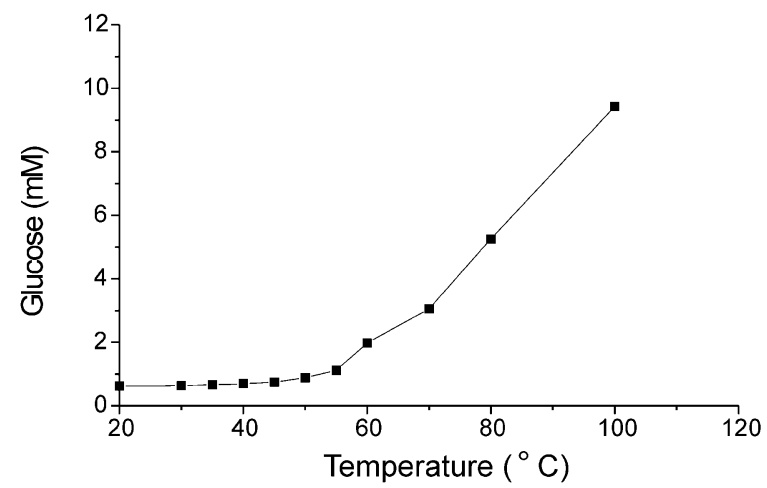

Fig. 3. Detection of glucose from LG in culture fluids of $\mathrm{pH} 2$ at an initial LG concentration of $100 \mathrm{mM}$.

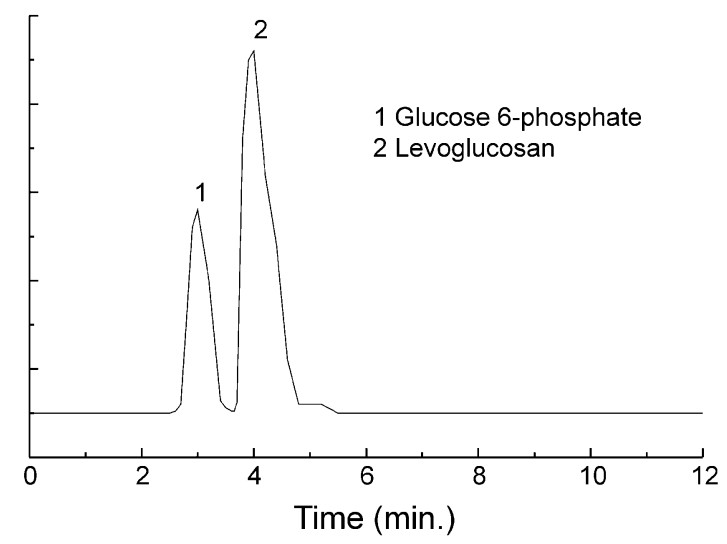

Fig. 4. Detection of glucose 6-phosphate by HPLC equipped with an ODS-18C column.

there would have been a peak of enzyme activity with the increase of temperature if this special enzyme was present.

\subsubsection{Verification of LG kinase}

The reaction mixture composed of cell extracts and $\mathrm{LG}$ at $\mathrm{pH}$ 9.3, in which no formation of glucose was detected, was mixed with $2 \mathrm{mM}$ ATP and $10 \mathrm{mM} \mathrm{MgCl}_{2}$, and then was incubated for $30 \mathrm{~min}$ at $30^{\circ} \mathrm{C}$. The product was analyzed by HPLC (Fig. 4). The first peak eluted had the same retention time as that of a standard glucose 6-phosphate. Using a glucose 6-phosphate dehydrogenase coupling system, formation of glucose 6-phosphate in the reaction

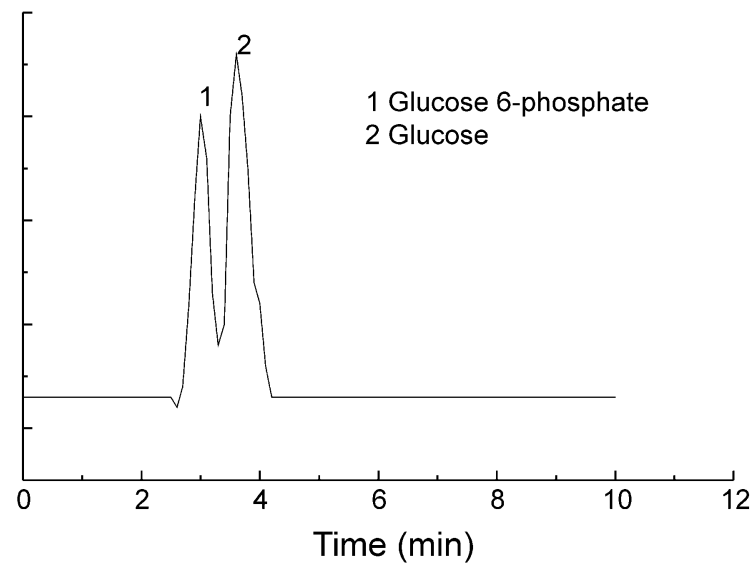

Fig. 5. Detection of glucose by HPLC (equipped with an ODS-18C column) formed by the addition of glucose 6-phosphatase to the reaction mixture composed of LG and partially purified LG phosphorylation enzyme.

mixture above containing ATP and $\mathrm{Mg} 2^{+}$could also be detected. Furthermore, after incubating for $2 \mathrm{~h}$, no LG could be detected and the concentration of glucose 6-phosphate reached its maximum value.

Further experiments were carried out to characterize this LG phosphorylation enzyme and the product. In these experiments, LG-phosphorylating enzyme, partially purified by an ion-exchange chromatography, was used instead of the crude cell extracts in order to eliminate the effect of phosphoglucomutase and 6-phosphogluconate dehydrogenase on the LG-phosphorylation enzyme detection. After a complete reaction for $2 \mathrm{~h}$, the reaction mixture was stopped by heating in a boiling water bath for $5 \mathrm{~min}$, mixed with glucose 6-phosphatase, incubated for $30 \mathrm{~min}$ at $30^{\circ} \mathrm{C}$, and the product was detected by HPLC (Fig. 5). The second peak eluted in Fig. 5 had the same retention time as that of a standard glucose. Since this product could also be detected by glucose oxidase and peroxidase coupling system (data not shown), it was considered to be glucose.

Results above showed that the activity of this enzyme acting on LG depended on the presence of $\mathrm{Mg}^{2+}$ and ATP, and that the product formed was glucose 6-phosphate. Therefore, A. niger CBX-209 should have one active protein phosphorylating LG, that can be considered to be an LG kinase, during its citric acid production. 


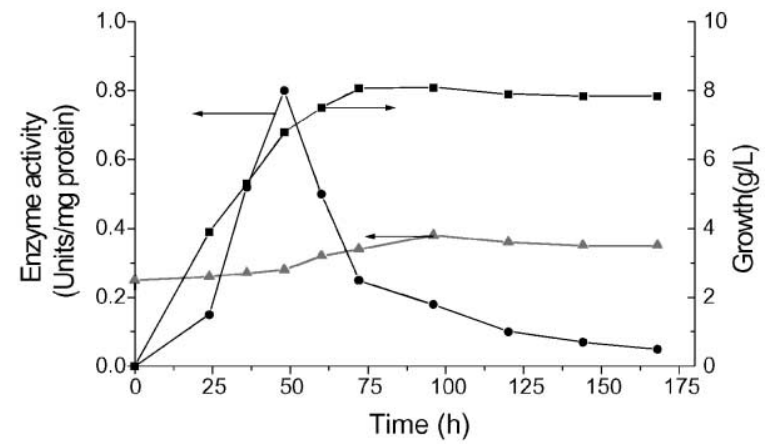

Fig. 6. Time-course changes in LG kinase and hexokinase activities of $A$. niger $C B X-209$ during citric acid fermentation on LG. Growth, (O) LG kinase activity and $(\boldsymbol{\Delta})$ hexokinase activity.

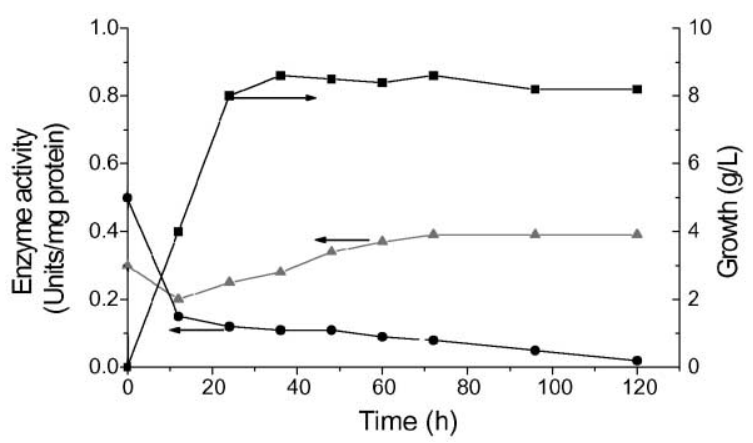

Fig. 7. Time-course changes in LG kinase and hexokinase activities of $A$. niger $C B X-209$ during citric acid fermentation on glucose.

$(\square)$ Growth, $(\bigcirc)$ LG kinase activity and $(\boldsymbol{\Delta})$ hexokinase activity.

\subsection{Regulatory properties of LG kinase and hexokinase in A. niger $C B X-209$}

A. niger $C B X-209$ precultured on glucose for $24 \mathrm{~h}$ was transferred and cultivated on the LG medium with shaking at $35^{\circ} \mathrm{C}$ and LG kinase and hexokinase activities were calculated (Fig. 6). From this figure, it can be seen that LG kinase activity increased along with the cell growth, reached the maximum at the late exponential growth phase, and then decreased. Also, as shown in Fig. 6, the specific activity of LG phosphorylation exceeded that of glucose phosphorylation. These results indicated the inductive nature of LG kinase synthesis and the constitutive nature of hexokinase synthesis, respectively. Fig. 7 showed the time-course changes of LG kinase and hexokinase in $A$. niger $C B X-209$ growing on glucose. When the cells grown on LG were used as the seed culture, LG kinase activity decreased rapidly until the middle exponential growth phase on glucose, and then maintained at a low level during the fermentation. It can also be seen from this figure that although both LG kinase and hexokinase activities decreased until the middle exponential growth phase, the rate of decrease in LG kinase was larger than that in hexokinase activity. Thereafter, hexokinase activity increased gradually.

\section{Conclusion}

The development of mutant CBX-209 for citric acid production has shown the possibility of evolving appropriate fungal mutants for citric acid production in the LG medium. For other fungi that could grow on LG, development of their mutants might also be necessary, because low or even no yields of their useful metabolites might be produced when using LG as carbon and energy source.

The mutant, $A$. niger $C B X-209$, needed a higher nitrogen concentration to achieve maximum citric acid yield in an LG medium than that on glucose medium. On the other hand, like glucose, high concentrations of $\mathrm{LG}>8 \%$ were inhibitory to citric acid production. Further studies for application to fed-batch culture might be expected to improve the production efficiency of this mutant and to lower the cost.

As to the metabolism of LG during its citric acid fermentation, although LG could be easily hydrolyzed to glucose with acid, LG-hydrolyzing activity could not be detected, either in cells of this mutant or in its culture fluids. Otherwise, direct phosphorylation to glucose 6-phosphate from LG was detected by HPLC in the reaction with the cell extracts or partly purified enzyme. Since this enzyme also needed ATP and $\mathrm{Mg}^{2+}$ like hexokinase in this mutant, it was believed to be a special kind of kinase, i.e. LG kinase.

LG kinase and hexokinase in $A$. niger $C B X$-2 were regulated in different ways when it was grown on different carbon sources. The level of LG kinase activity changed depending upon the carbon sources used, showing an inductive nature of its synthesis by LG. Since LG kinase had quite a strict substrate specificity and phosphorylated LG exclusively, it could not contribute to citric acid production in the glucose medium. However, in an LG medium, although hexokinase had 
no effect on LG, it might have a slight contribution to the overall citric acid conversion, because a little amount of LG was converted into glucose during fermentation, especially when $\mathrm{pH}$ of the culture was lowered to about 2. A. niger $C B X-2$ cultivated in $\mathrm{LG}$ medium needed a longer fermentation time to consume the substrate, possibly owing to the slower rate for this mutant to take LG into the inner cells than that of glucose.

\section{Patent}

1. Hongxun Zhang, Xuliang Zhuang. A new and simple method for the purification and preparation of levoglucosan from pyrolysis oils of cellulose. 2000:Chinese Patent, Application No.: 00107956.5 .

\section{Acknowledgements}

We thank Z.H. Bai and Z.S. Yu, for their assistance in the preparation of levoglucosan.

\section{References}

[1] Ward RB. Levoglucosan. In: Whistler RL, Wolfrom ML, BeMiller JM, editors. Methods in carbohydrate chemistry, New York: Academic Press, 1963. p. 394-6.

[2] Gander M, Rapp KM, Schiweck H. Process for preparing 1,6- $\beta$-D-anhydroglucopyranose (levoglucosan) in high purity. US Patent, No: 5023330, 1991.

[3] Wolff IA, Olds DW, Ill P. Levoglucosan production by pyrolysis of pretreated starches. US Patent, No: 3478012, 1969.

[4] Piskorz J, Scott DS, Radlein D. Composition of oils obtained by fast pyrolysis of different woods. In: Soltes EJ, Milne TA, editors. American Chemical Society Symposium, series no. 376. Washington DC, USA: American Chemical Society, 1988. p. 167-78.

[5] Piskorz J, Radlein D, Scott DS, Czernik S. Pretreatment of wood and cellulose for production of sugars by fast pyrolysis. Journal of Analytical and Applied Pyrolysis 1989;16:127-36.

[6] Scott DS, Radlein D, Piskorz J, Majerski P. Potential of fast pyrolysis for the production of chemicals. In: Hogan E, Roberts J, Grassi G, Bridgewater AV, editors. Biomass thermal processing. London, Chamelon Press, 1992. p. 171-8.

[7] Prosen EM, Radlein D, Piskorz J, Scott DS, Legge RL. Microbial utilization of levoglucosan in wood pyrolysate as a carbon and energy source. Biotechnology and Bioengineering $1993 ; 42: 538-41$.
[8] Zhang HX, Zhuang XL. A new and simple method for the purification and preparation of levoglucosan from pyrolysis oils of cellulose. Chinese Patent, Application No: 00107956.5, 2000.

[9] Moens L. Isolation of levoglucosan from pyrolysis oil derived from cellulose. US Patent No: 5371212, 1994.

[10] Nakagawa M, Sakai Y, Yasui T. Itaconic acid fermentation of levoglucosan. Journal of Fermentation Technology 1984;62:201-3.

[11] Kitamura Y, Abe Y, Yasui T. Metabolism of levoglucosan(1,6-anhydro- $\beta$-D-glucopyranose) in microorganism. Agricultural and Biological Chemistry 1991;55: $515-21$

[12] Kitamura Y, Yasui T. Purification and some properties of levoglucosan (1,6-anhydro- $\beta$-D-glucopyronose) kinase from the yeast sporolomyces salmonicolor. Agricultural and Biological Chemistry 1991;55:523-9.

[13] Yasui T, Kitamura Y, Nakahara K, Abe Y. Metabolism of levoglucosan (1,6-anhydro- $\beta$-D-glucopyranose) in bacteria. Agricultural and Biological Chemistry 1991;55:1927-9.

[14] Nakahara K, Kitamura Y, Yamagishi Y, Shoun H, Yasui $\mathrm{T}$. Levoglucosan dehydrogenase involved in the assimilation of levoglucosan in Arthrobacter sp. I-552. Biosciences and Biotechnology in Biochemistry 1994;58:2193-6.

[15] Xue M, Qi H, Zhang H, Lei Z, Zhu X. Citric acid production from corn starch by submerged fermentation. In: Teo WK, Yap MGS, Oh SKW, editors. Better living through innovative biochemical engineering. Singapore: Continental Press Pte Ltd. 1994. p. 104-6.

[16] Maitra PKA. Glucokinase from Saccharomyces cerevisiae. Journal of Biological Chemistry 1970;245:2423-31.

[17] Bradford MM. A rapid and sensitive method for the quantitation of microgram quantities of protein utilizing the principle of protein-dye binding. Analytical Biochemistry 1976;72:248-54.

[18] Papadopoulas WM, Hess WC. Determination of neuraminic(sialic) acid, glucose and fructose in spinal fluid. Archives of Biochemistry and Biophysics 1960;88:167-9.

\section{For further reading}

\section{Publications}

1. Xuliang Zhuang, Hongxun Zhang et al., 2000. Effect of Tween 80 on the growth of Lactococcus lactis SM526 and Nisin activity. Engineering Chemistry \& Metallurgy, 2000;21(2):145-8.

2. Xuliang Zhuang, Hongxun Zhang et al., Effect of major factors of fermentation medium on Nisin production. Engineering Chemistry \& Metallurgy, 2000:21(1):93-7.

3. Hongxun Zhang, Xuliang Zhuang, 1999. Studies on bioconversion of levoglucosan derived from 
pyrolysis of cellulose. In: Zhu QS editor. Green chemistry. Proceedings of the Second International Workshop on Green Chemistry. Chengdu: Sichuan University Press. p. 81-5.

4. Xuliang Zhuang, Guirong MA. The relationship between the special structure and the function of Nisin. Chemistry of Life. 1998;18(2):37-9.

5. Jian Kong, Xuliang Zhuang et al., The effect of SL-probiotics on experimental hyperlipidemia. Journal of ShanDong University. (Natural Science), 1998;33(1):106-9.

6. Jian Kong, Xuliang Zhuang et al., Studies on the characters of Streptococcus lactis SB900 produced SL-probiotics. Journal of Shandong University (Natural Science), 1996;31(4):454-9.
Xuliang Zhuang, born on May 23, 1970, received the Bachelor's degree in Microbiology Engineering and the Master's degree in Fermentation Engineering in July 1989, and July 1998, respectively, from the School of Life Sciences, Shandong University, Junan. $\mathrm{He}$ has been a Ph.D. candidate of Biochemical Engineering at Research Center for Eco-Environmental Sciences, Chinese Academy of Sciences, Beijing, since September 1998. He has been doing research in the field of Biochemistry from August 1989 to 1995, at the Institute of Microbiology, Shandong University, Junan. His publications and a patent are listed below. 